\title{
The Waveguide in the Mantle of the Earth and its probable physical nature
}

\author{
by Magnitsky V. A., Khorosheva V. V. $\left({ }^{*}\right)$ \\ Ricevuto il 7 dicembre 1960
}

As far as we can see, B. Gutenberg was the first who points out the possibility of existence of a low-velocity layer in the upper parts of the Mantle (Gutenberg, 1926). It is quite obvious that such a lowvelocity layer can act as channel conducting seismic energy. This was established by Caloi (1953, 1954) and Press and Ewing (1954, 1955).

In present paper we report results of further investigations in that topic based on data from seismograms of 9 earthquakes recorded by seismic stations of USSR with epicentral distances in the range $22^{\circ}$ to $150^{\circ}$ (Table 1 ).

There were used only seismograms with epicentral distances in which no overlap of $P_{a}$ and $S_{a}$ with any other phase could be suspected.

Almost in every seismogram $P_{a}$ and $S_{a}$ phases can be clearly detected (Fig. 1), however, the first arrival of the phase is often not very distinct. This is probably the main cause of considerable scattering in results. In Figure 2 are plotted travel times versus $\Delta$. In spite of scattering of arrival times it is apparent that travel-time curves for $P_{a}$ and $S_{a}$ are straight lines, their equations are as follows

$$
\begin{array}{ll}
t^{m}=0,9558+0,2205 \Delta^{o} & P_{a} \\
t^{m}=0,3780+0,4180 \Delta^{o} & S_{a}
\end{array}
$$

This gives velocity $8,3 \mathrm{~km} / \mathrm{sec}$ and $4,47 \mathrm{~km} / \mathrm{sec}$ for $P_{a}$ and $S_{a}$ respectively.

Periods of $P_{a}$ are in range 5-12 sec, those of $S_{a}$ in range $7-30$ sec.

(*) Paper read at the Helsinky Assembly of the I.U.G.G., 1960. 
There is familiar equation connecting amplitude $A$ of seismic wave with distance $r$ from the source

$$
A=C r^{-n} e^{-\alpha r}
$$

$C$ being constant, $\alpha$-absorption coefficient, $n$-depends on the type of wave. For plane wave $n=0$, for spherical wave $n=1$, for cylindrical

Table 1

\begin{tabular}{|c|c|c|c|c|c|c|}
\hline $\mathrm{Nu}$ & Date & $\lambda$ & $\varphi$ & $\begin{array}{c}\text { Depth } \\
\mathrm{km}\end{array}$ & mI & $a \mathrm{~km}^{-1}$ \\
\hline 1 & $11 / X \quad-56$ & $151,3 \mathrm{E}$ & $45,4 \mathrm{~N}$ & 100 & $71 / 4-71 / 2$ & 0,000143 \\
\hline 2 & 18/VIII -54 & $175,0 \mathrm{~W}^{\top}$ & $21,5 \mathrm{~S}$ & 170 & $71 / 4-71 / 2$ & 0,000146 \\
\hline 3 & $23 / \mathrm{V} \quad-50$ & $178,5 \mathrm{~W}$ & $15,5 \mathrm{~S}$ & 400 & $6^{3} / 4^{-7}$ & 0,000139 \\
\hline 4 & $7 / \mathrm{VI} \quad-5$ & $152,5 \mathrm{E}$ & $4,0 \mathrm{~S}$ & 460 & $71 / 4^{-7} 1 / 2$ & 0,000156 \\
\hline 5 & $20 /$ I I $\quad-54$ & $125,0 \mathrm{E}$ & $7,5 \mathrm{~S}$ & 520 & $61 / 2-7$ & 0,000184 \\
\hline 6 & $16 /$ VIII -55 & $155,0 \mathrm{E}$ & $6,0 \mathrm{~S}$ & 200 & $6^{3} / 4-71 / 2$ & \\
\hline 7 & $31 / \mathrm{I} 1 \mathrm{I} \quad-55$ & $124,0 \mathrm{E}$ & $8,0 \mathrm{~N}$ & 50 & $-71 / 4$ & \\
\hline 8 & $29 /$ I I $\quad-54$ & $3,5 \mathrm{~W}$ & $37,0 \mathrm{~N}$ & 640 & $71 / 4-71 / 2$ & \\
\hline 9 & $21 /$ III $\quad-54$ & $95,0 \mathrm{E}$ & $24,5 \mathrm{~N}$ & 170 & $\begin{array}{ll}7 & -71 / 2\end{array}$ & \\
\hline
\end{tabular}

one $n=0,5$. If we denote $A_{o}, r_{o}$ amplitude and distance at any arbitrary fixed point [1] becomes

$$
\frac{\ln A_{o} / A}{\ln r / r_{o}}=n+\alpha \frac{r-r_{o}}{\ln r / r_{o}}
$$

Plotting empirical values of [2] for earthquake of 11 October 1956 on Fig. 3 we obtain a straight line with $n=0,52$ and $\alpha=0,00014 \mathrm{~km}^{-1}$. The inference is the $P_{a}$ phase corresponds to a cylindrical wave. Hence it is evident from both the travel times and amplitudes that $P_{a}$ phase is connected with the surface or channel wave. Velocity obtained excludes the first supposition, consequently we must adopt the channel type to the wave in consideration.

Unfortunately all other earthquakes have epicenters at great distances relatively to our stations. So we must use instead of [1] equation

$$
A=C(\sin \Delta)^{-1 / 2} \cdot e^{-a \Delta R}
$$


In [3] one takes in consideration the spherical shape of the channel. In last column of table 1 are plotted $\alpha$ obtained by [3] for other earthquakes. These results are in apparent agreement with our previous conclusions.

But what is the cause of the formation of the low-velocity layer? The common supposition is that it is due to prevailing effect of increase

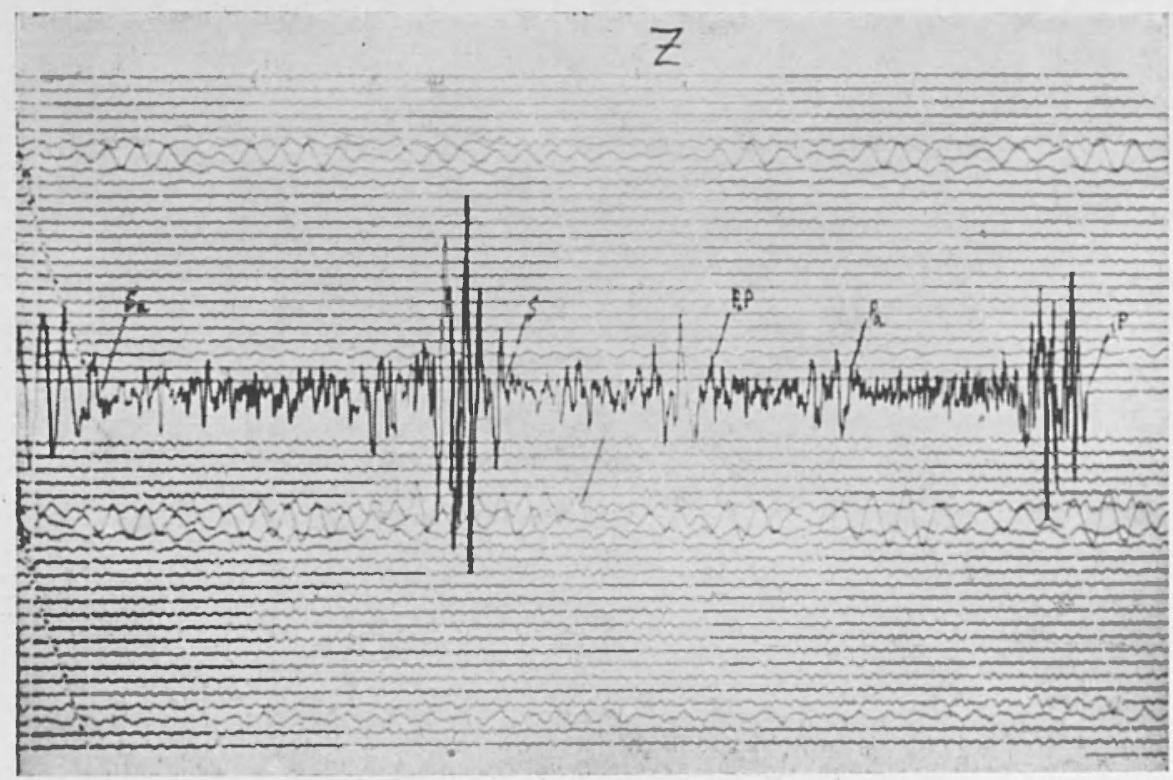

Fin. 1. - Example of records of $P_{a}$ and $S_{a}$ phases (Farthquake 29/111-1954, $6^{\mathrm{h}} 1 \overline{7}^{\mathrm{m}} 06^{\mathrm{s}}$, epicentral distance $\left.A=31^{\circ}, 3\right)$.

of temperature as compared with effect of increase in pressure. Velocity $v$ would have minimum if $d v / d h=0$.

This gives

$$
\frac{d T}{d h}--\frac{\left(\frac{\partial v}{\partial P}\right)_{T}}{\left(\frac{\partial v}{\partial T}\right)_{P}} \cdot \varepsilon g
$$

Using the data from the work of Hughes and Cross (1951) we deduce the critical value of $d T / d h$ in range 7 to 10 degrees per $\mathrm{km}$. This seems to be too much. But if we take into consideration the temperature de- 
pendance of thermal conductivity (Peierls, 1955, Dugdall and McDonald, 1955, Clark, 1956) in form

$$
\varkappa=\frac{A}{T}+B T^{3}
$$

we infer that $*$ has a minimum at the depths $50-100 \mathrm{~km}$ (Lubimova, 1958). Let us take $1,2 \cdot 10^{-6} \mathrm{cal} / \mathrm{cm}^{2} \mathrm{sec}$ as average for the heat flow at

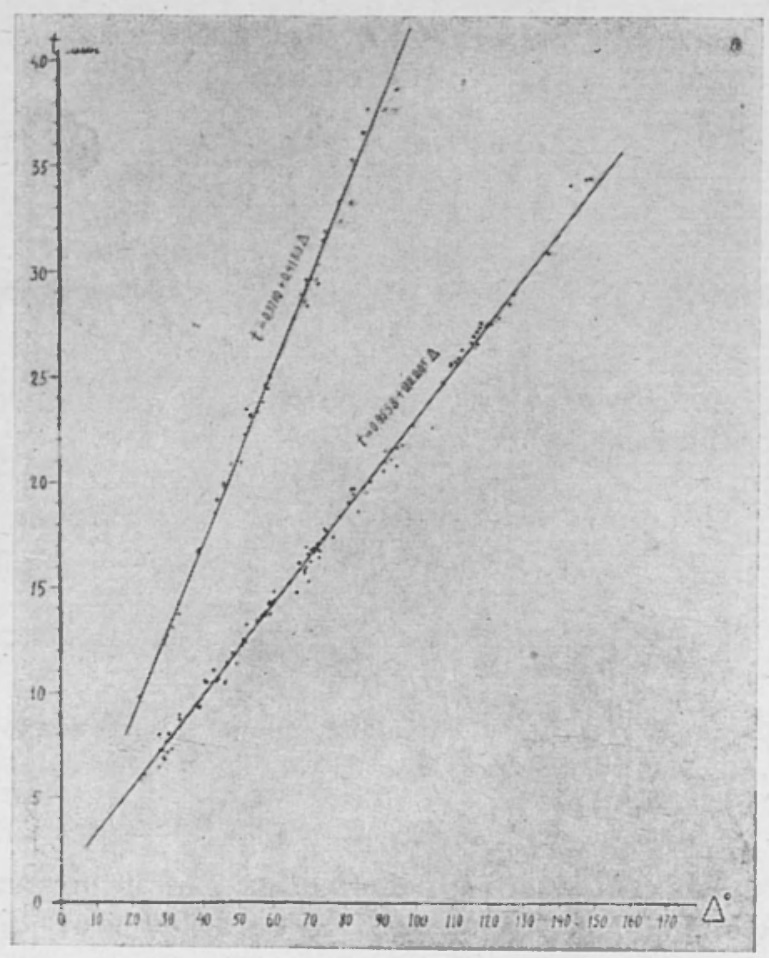

Irig. 2. - Traval-times for $P_{a}$ and $S_{a}$.

the Earth's surface. Adopting usual content of heat generation in various types of rocks we find that gradient $d T / d h$ can run up to $18 \mathrm{deg} / \mathrm{km}$ at $h=100 \mathrm{~km}$ beneath the continental crust and $15 \mathrm{deg} / \mathrm{km}$ at $h=50$ $\mathrm{km}$ beneath the oceanic crust. These values seem to be quitesu fficient to explain the formation of a low-velocity layer. 
Another explanation assumes the vitrification of the material of the mantle at respective depths. For the volume increase by vitrification we can write (Frenkel, 1950)

$$
\frac{V-V_{i}}{T_{0}}=e^{-\frac{E}{k T}}
$$

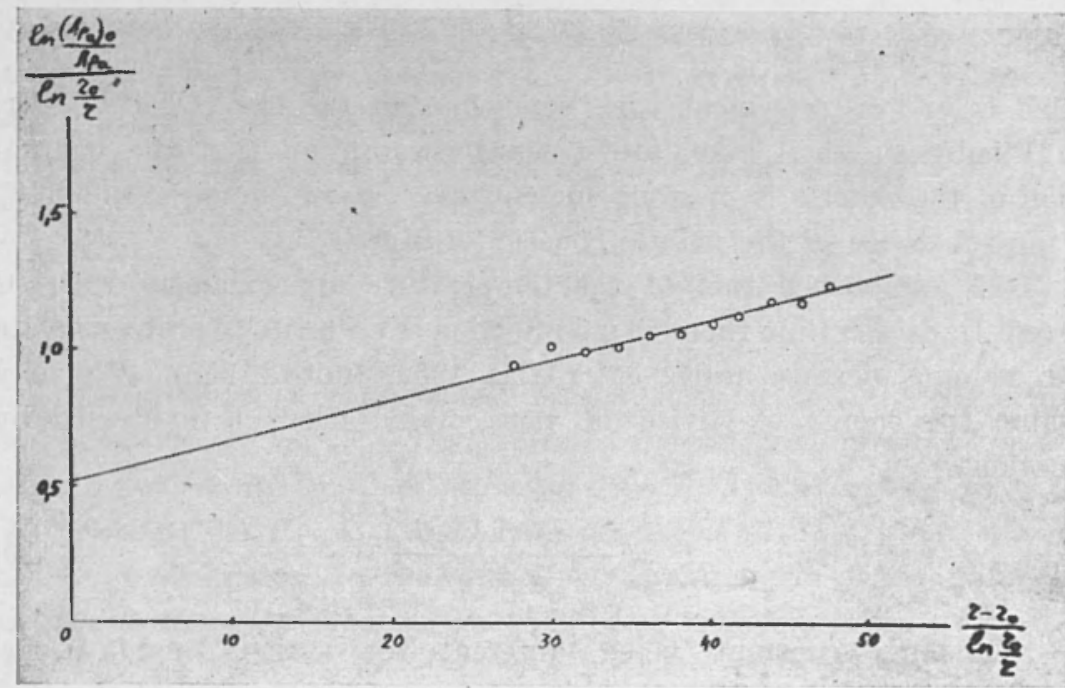

Fig. 3. - Determination of $\alpha$ and $n$ (Earthquake $11 / \mathrm{X}-1956,2 \mathrm{~h} 24^{\mathrm{m}} 32^{\mathrm{s}}$ ).

$E$ denotes energy of activation. From [6] we obtain by differentiation

$$
\frac{\Delta K}{K_{o}}=\frac{\Delta V}{V_{o}} \ln \frac{\Delta V}{V_{o}} \cdot \frac{\partial \ln E_{o}}{\partial \ln V}
$$

$K$ - incompressibility, $E_{0}$ - energy of activation at zero pressure.

Derivative

$$
\frac{\partial \ln E_{0}}{\partial \ln V^{-}} \approx 2,5
$$

(Zharkov, 1958).

$$
\begin{aligned}
& \text { Denoting } / \frac{\bar{K}}{\varrho}=v \text { we find } \\
& \qquad \frac{d v}{v}-\frac{1}{2}\left(\frac{d K}{K}+\frac{d V}{V}\right)
\end{aligned}
$$


Now it follows

$$
\frac{d v}{v}=\frac{1}{2} \frac{\Delta V}{V_{0}}\left(1+\ln \frac{\Delta V}{V_{0}} \cdot \frac{\partial \ln E_{o}}{\partial \ln V}\right)
$$

For dunite $\frac{\Delta V}{V_{0}} \approx 2^{\circ} \%$, consequently we hare

$$
\frac{d v}{v} \approx 6 \%
$$

which is in fair agreement with conditions in the low-velocity layer.

Finally we shall take into account assumption that the composition of the mantle is of stone meteorites. So we suppose the $30 \%$ of the substance of the mantle consists of $\mathrm{MgSiO}_{3}$.

It is established that at the temperature approximatly $1000^{\circ} \mathrm{C}$ there is transition from rhombic modification of enstatite to protoenstatite with volume increase nearly $3 \%$ (Atlas, 1952, Smith, 1958). We may assume the energy of lattice of both modifications is expressed by equation

$$
U=-\frac{A \rho^{2}}{r}+\frac{R}{r^{n}}
$$

A - Madelung constant being different for various modifications. $B$ and $n$ are determined by the nature of repulsive forces. As the character of repulsive forces do not change during transition mentioned above, we can suppose in first approximation $B$ and $n$ being the same for both modifications.

We have

$$
\frac{\boldsymbol{K}}{V}=-\frac{d p}{d r} \cdot \frac{d r}{d V}
$$

From [10] and [11] it follows

$$
\Delta\left(\frac{K}{\varrho}\right) \cdot \frac{K}{o}=\frac{n}{3} \cdot \frac{\Delta \varrho}{\varrho}
$$

For most causes $n$ is in the range 6 to 9 , so decrease in velocity in lowvelocity layer can be suspected to be about $3 \%$.

In conclusion it is necessary to emphasise that all three causes of formation of low-velocity layer seem to be quite adequate to explain it and it is impossible to choose one of them without any additional data. 


\section{$S U M A R Y$}

Records on seismic stations in USSR confirm the existance of $P_{a}$ and $S_{a}$ phases in no correspondance to any well known phase. The traveltime curves of $P_{a}$ and $S_{a}$ phases are obtained as being straight lines. Velocities of $P_{a}$ and $S_{a}$ are $8,30 \pm 0,03 \mathrm{~km} / \mathrm{sec}$ and $4,57 \pm 0,03 \mathrm{~km} / \mathrm{sec}$ respectively. Decrcase in amplitudes as well as the form of travel-time curves indicates that $P_{a}$ and $S_{a}$ are cylindrical waves. It is supposed $P_{a}$ and $S_{a}$ travelling along a low-velocity channel in astenosphere. Formation of such a layer is due to vitrification of material at the depth of some $100-200 \mathrm{~km}$.

\section{RIASSUNTO}

Le registrazioni effettuate nelle stazioni sismiche in U.R.S.S. confermano l'esistenza di fasi $P_{a}$ ed $S_{a}$ senza corrispondenza con alcuna fase gia nota. Le curve del tempo di cammino delle $P_{a}$ ed $S_{a}$ risultano linee rette. Le velocita delle $P_{a}$ ed $S_{a}$ sono rispettivamente di $8,30 \pm 0,03 \mathrm{~km} / \mathrm{sec} e$ $4,57 \pm 0,03 \mathrm{~km} / \mathrm{sec}$. Le diminuzioni di ampiezza e la forma della curva del tempo di tragitto indicano che le $P_{a}$ ed $S_{a}$ sono onde cilindriche. Si suppone che le $P_{a}$ ed $S_{a}$ si muovano su un canale a bassa velocita nella astenosfera. La formazione di un simile strato e dovuta alla vetrificazione del materiale alla profondita di circa $100-200 \mathrm{~km}$.

\section{REFERENCES}

Atlas L., The polymorphysm of $\mathrm{MgSiO}_{3}$. "Journ. Geol.", 60, 2, (1952). Clark S. P., Effect of radiative transfer of temperature in the Earth. "Bull. Geol. Soc. Amer.", 67, 5, (1956).

Calor P., Onde longitudinali e trasversali guidate dell'astenosfera. "Rend. Acad. Naz. Linc. ", ser. 8, 15, 6, (1953).

-- L'astenosfera come canale-guida dell'energia sismica. "Ann. Geof. ", 7, 4, (1954).

Dugdall, McDonald Q., Lattice thermal conductivity. "Phys. Rev. ", 98, 6, (1955).

Frenkel J. I., Introduction in the theory of metals. Moseow (in Russian) 1950.

Gutenberg B.. Untersuchungen zur Frage, bis zu weleher Tiefe die Erde kristallin ist. "Zeitschr. Geophys. ", 2, 1, (1926). 
Hughes D. S., Cross J. H., Elastic wave velocities in rocks at high pressures and temperatures. "Geophys. ", 16, 4, (1951).

Luвimova H. A., Thermal history of the Earth with consideration of the va. riable thermal conductivity of its mantle. "Geoph. Journ. Roy. Astr. Soc. ", 1, 2, (1958).

Peierls R. E., Quantum theory of solids. Oxford, 1955.

Press F., Ewing M., $P$ and $S$ velocities at great distances. "Bull. Geol. Soc. Amer. ", 65, 1, (1954).

- - Waves with $P$ and $S$ velocity at great distances. "Proc. Nat. Acad. Sc. ", 41, 1, (1955).

Sмiтн J. V., Orystal structure of protoenstatite. "Bull. Geol. Soc. Am. ", 69, 12,2 , (1958).

Zharkov V. N., On electrical conductivity and temperature of the Earth's mantle. "Proc. Ac. Sc. USSR", ser. Goophys. 4 (in Russian) 1958. 